American Medical Journal 2 (1): 29-31, 2011

ISSN 1949-0070

(C) 2011 Science Publications

\title{
Problem-Based Clinical Cases Increase the Level of Pharmacology Education for Physiotherapy Students
}

\author{
Yazun Bashir Jarrar \\ Departments of Pharmacology, Faculty of Pharmacy, \\ Al-Jouf University, Skaka, Saudi Arabia
}

\begin{abstract}
Problem statement: Pharmacology course is mandatory course for physiotherapy students in most of Middle Eastern Universities. Most of physiotherapy students believe that they should not study pharmacology course during bachelor degree. In addition, their marks in pharmacology course were lower than other medical basic courses. Approach: The present study investigated how to improve the level of pharmacology education for physiotherapy students by introducing theoretical clinical cases showed the effect of physiotherapy on drug response. Results: The present study showed a significant difference in student performance before and after adding these clinical cases. Conclusion/Recommendations: This study concluded that addition of theoretical clinical cases which show the effect of physiotherapy techniques on drugs activity improved physiotherapy students performance in studying pharmacology.
\end{abstract}

Key words: Pharmacology education, physiotherapy students, medical basic courses, clinical cases

\section{INTRODUCTION}

Pharmacology is the study of the effect of the chemical compounds on the biological system (Filip et al., 2007). It is a basic science for medical education where physician, pharmacist and nurse play a major role in prescribing, dispensing and administration of the drug to patients, respectively. However, medical stuff in clinical centers includes physiotherapists and laboratory analysts play a minor role in drug prescription and administration. However, physiotherapist should be familiar about how physiotherapy could affect on drug therapy or versa vice (Dias et al., 2010). It is reported that massaging of some areas on the body increases the absorption of some drugs on the site of administration. This increasing of absorption may be dangerous in some cases when the drug manages critical parameters in the body. It was reported that increasing in absorption rate of insulin injected by sub-dermal route induced hypoglycemia and might lead to coma (Calabrese, 2008). In addition, cold therapy reported to decrease drug absorption at site of administration (Tortorici et al., 2007). Also, iontophoresis was reported to affects pharmacokinetics parameters of certain drugs (Akomeah, 2010; Pescina et al., 2010; Vaghani et al., 2010).

Pharmacology course is mandatory for physiotherapy students in most of Universities. It is taught in a classical way in which a drug class lecture consists of pharmacodynamics, pharmacokinetics, main drugs, clinical uses and side effects. Lecturers of pharmacology noted that physiotherapy students get the lowest grades in pharmacology course in comparison with other basic medical courses during bachelor degree study. Many lecturers, especially in Middle Eastern Universities, tried to solve this problem by reducing the number of chapters and units which should be taught during pharmacology course for physiotherapy students. However, there was not a significant increasing in the level of pharmacology education for physiotherapy students.

Studies about pharmacology education for physiotherapy students are limited, if absent. Accordingly, the aim of the present study is to evaluate an educational scientific method for increasing the level of teaching pharmacology course for physiotherapy students.

\section{MATERIALS AND METHODS}

The present study was done at second studying semester on 2010, in Aljouf University, Skaka, Saudi Arabia. The syllabus of the first month was a classical way in teaching pharmacology for physiotherapy without addition of theoretical clinical parts. In the second month, the way of teaching pharmacology was changed by which a simple lecture for drug group consisted of: Pharmacodynamic, clinical uses, side effects and theoretical clinical cases about the effect of physiotherapy on drug activity were added for first 
time. These clinical cases were published in highly respected journals. After that the evaluation of student's performance (55 physiotherapy students belong to Aljouf University, Skaka-Saudi Arabia) in pharmacology course was done by putting different type of questions represented 3 different parts in the second exam at the same studying semester:

Part one: Represented pharmacodynamics of the drug class

Part two: Represented clinical uses and side effects

Part three: Represented clinical cases about the effect of physiotherapy techniques on the activity of some drugs

The average of student's performance in the whole exam was calculated and compared with first exam marks at first month (without clinical cases, part three).

The average marks for each part of the exam was calculated and converted to percentage (\%) by dividing the correct answered questions to the total questions in each part and multiplied by 100 .

Z-test, $\mathrm{p}<0.05$ was used as a comparative statistical tool for comparison of the student's marks before and after addition of clinical cases part.

\section{RESULTS}

Fifty five students were evaluated for pharmacology course before and after adding of theoretical clinical cases at the same studying semester. The results showed a significant increasing in the average of total marks in pharmacology exam in the second month after adding of clinical cases part to the syllabus (Table 1). In addition, the marks of students in the clinical cases part were significantly higher than the marks of other two parts (pharmacodynamics and clinical uses) in the second exam at the same studying semester (Table 2).

Table 1:The average of total marks in the second month after adding of theoretical clinical cases part to the syllabus

\begin{tabular}{|c|c|}
\hline $\begin{array}{l}\text { The total average marks for } \\
\text { first month (without clinical } \\
\text { cases part) out of } 30\end{array}$ & $\begin{array}{l}\text { The total average marks for } \\
\text { second month (with clinical } \\
\text { cases part) out of } 30 \%\end{array}$ \\
\hline 16 & $24 *$ \\
\hline \multicolumn{2}{|l|}{ *: Statistical higher, $\mathrm{p}$-value $<0.05$} \\
\hline \multicolumn{2}{|c|}{$\begin{array}{l}\text { Table 2: The average of total marks in the second month exam after } \\
\text { adding of theoretical clinical cases part to the pharmacology } \\
\text { syllabus }\end{array}$} \\
\hline $\begin{array}{l}\text { Parts of pharmacology exam for } \\
\text { physiotherapy students }\end{array}$ & $\begin{array}{l}\text { Average of marks for each } \\
\text { part in the exam } 100 \%(\%)\end{array}$ \\
\hline Pharmacodynamics & 20 \\
\hline Clinical uses and side effect & 47 \\
\hline $\begin{array}{l}\text { Clinical cases about the effect of } \\
\text { physiotherapy techniques on the } \\
\text { activity of some drugs }\end{array}$ & $85^{*}$ \\
\hline
\end{tabular}

\section{DISCUSSION}

Most of the physiotherapy students believe that it is unnecessary to study pharmacology course during bachelor degree and this course should be restricted for medicine and pharmacy students. However, pharmacology course is essential course for physiotherapist where they are in direct contact with a patient who takes medicine in most cases. After changing the way of teaching pharmacology course for physiotherapy students and introducing the theoretical clinical cases about the effect of some techniques used in physiotherapy on the activity of some drugs, students attitude toward the importance of studying pharmacology course increased and they recognized from problems in the clinical cases how was good background in pharmacology helping in solving some problems faced physiotherapists.

The present study showed that problem-based learning system increased the level in teaching pharmacology for physiotherapy students where the overall marks were increased after addition of clinical cases part in which physiotherapy techniques affect drugs activity and therapy outcome (Alhaqwi et al., 2010). These cases practiced them on problems which may face it in future where they need to be familiar about some clinical properties of the drug and pharmaceutical route of administration (Banning, 2003). These problem-based learning increased the behavior for physiotherapy students to learn more about drugs which are used commonly for chronic and acute diseases (Carrega and Byrne, 2010).

This study reported that pharmacodynamics part in the exams which depended on the biochemistry of the drugs was associated with the lowest marks (Calderon et al., 2010). This might be due to the attitude toward pharmacodynamics of the drugs that it was not important for physiotherapist to know about it. In addition, biochemistry was not taught before pharmacology course for most of the students which might be the main reason for the low marks for the students in the pharmacodynamics part.

\section{CONCLUSION}

The present study concluded that addition of theoretical clinical cases which represent the effect of physiotherapy techniques on drugs activity and therapy outcome increased the level of pharmacology education for physiotherapy students. 


\section{REFERENCES}

Akomeah, F.K., 2010. Topical dermatological drug delivery: quo vadis? Curr. Drug Deliv., 7: 283-296. PMID: 20695839

Alhaqwi, A.I., H.T. van der Molen, H.G. Schmidt and M.E. Magzoub, 2010. Determinants of effective clinical learning: A student and teacher perspective in Saudi Arabia. Educ. Health. (Abingdon), 23: 369. PMID: 20853240

Banning, M., 2003. Pharmacology education: A theoretical framework of applied pharmacology and therapeutics. Nurse. Educ. Today., 23: 459-466. PMID: 12900195

Calabrese, E.J., 2008. Hormesis: Principles and applications for pharmacology and toxicology. Am. J. Pharmacol. Toxicol. 3: 59-71. DOI: 10.3844/ajptsp.2008.59.71

Calderon, R.M., L.X. Cubeddu, R.B. Goldberg and E.R. Schiff, 2010. Statins in the treatment of dyslipidemia in the presence of elevated liver aminotransferase levels: a therapeutic dilemma. Mayo. Clin. Proc., 85: 349-56. PMID: 20360293

Carrega, J. and M. Byrne, 2010. Problem-based scenarios to learn clinical teaching skills. Nurse. Educ., 35: 208-212. PMID: 20729680
Dias, M., N.M. Carneiro, L.A. Guerra, G.C. Velarde and P.A. de Souza et al., 2010. Effects of electroacupuncture on local anaesthesia for inguinal hernia repair: A randomised placebocontrolled trial. Acupunct. Med., 28: 65-70. PMID: 20615859

Filip, R., A. Harrison and S.G. Pierzynowski, 2007. A combined hytohemagglutinin and $\alpha$-pharmacology study of gut morphology and growth in older adult rats. Am. J. Pharmacol. Toxicol., 2: 170-177. DOI: 10.3844/ajptsp.2007.170.177

Pescina, S., G. Ferrari, P. Govoni, C. Macaluso and C. Padula et al., 2010. In-vitro permeation of bevacizumab through human sclera: Effect of iontophoresis application. J. Pharm. Pharm., 62: 1189-1194. PMID: 20796199

Tortorici, M.A., P.M. Kochanek and S.M. Poloyac, 2007. Effects of hypothermia on drug disposition, metabolism, and response: A focus of hypothermia-mediated alterations on the cytochrome P450 enzyme system. Crit. Care. Med., 35: 2196-2204. PMID: 17855837

Vaghani, S.S., M. Gurjar, S. Singh, S. Sureja and S. Koradia et al., 2010. Effect of iontophoresis and permeation enhancers on the permeation of an acyclovir gel. Curr. Drug. Deliv., 7: 329-333. PMID: 20695844 